\title{
ARTICLE
}

Acute myeloid leukemia

\section{Randomized phase-II trial evaluating induction therapy with idarubicin and etoposide plus sequential or concurrent azacitidine and maintenance therapy with azacitidine}

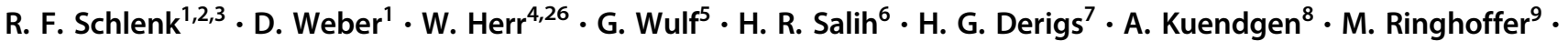 \\ B. Hertenstein ${ }^{10,11} \cdot$ U. M. Martens ${ }^{12} \cdot$ M. Grießhammer ${ }^{12} \cdot$ H. Bernhard ${ }^{13} \cdot$ J. Krauter $^{14} \cdot$ M. Girschikofsky ${ }^{15}$.

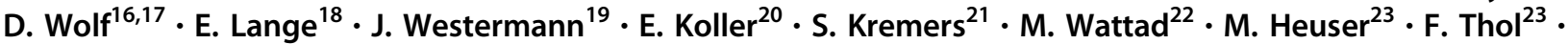 \\ G. Göhring ${ }^{24} \cdot$ D. Haase ${ }^{5} \cdot$ V. Teleanu ${ }^{1} \cdot$ V. Gaidzik ${ }^{1} \cdot$ A. Benner ${ }^{25} \cdot$ K. Döhner $^{1} \cdot$ A. Ganser ${ }^{23} \cdot$ P. Paschka ${ }^{1} \cdot$ H. Döhner ${ }^{1}$
}

Received: 2 December 2018 / Revised: 4 January 2019 / Accepted: 11 January 2019 / Published online: 6 February 2019

(c) The Author(s) 2019. This article is published with open access

\begin{abstract}
The aim of this randomized phase-II study was to evaluate the effect of substituting cytarabine by azacitidine in intensive induction therapy of patients with acute myeloid leukemia (AML). Patients were randomized to four induction schedules for two cycles: STANDARD (idarubicin, cytarabine, etoposide); and azacitidine given prior (PRIOR), concurrently (CONCURRENT), or after (AFTER) therapy with idarubicin and etoposide. Consolidation therapy consisted of allogeneic hematopoietic-cell transplantation or three courses of high-dose cytarabine followed by 2-year maintenance therapy with azacitidine in the azacitidine-arms. AML with CBFB-MYH11, RUNX1-RUNX1T1, mutated NPM1, and FLT3-ITD were excluded and accrued to genotype-specific trials. The primary end point was response to induction therapy. The statistical design was based on an optimal two-stage design applied for each arm separately. During the first stage, 104 patients (median age 62.6, range 18-82 years) were randomized; the study arms PRIOR and CONCURRENT were terminated early due to inefficacy. After randomization of 268 patients, all azacitidine-containing arms showed inferior response rates compared to STANDARD. Event-free and overall survival were significantly inferior in the azacitidine-containing arms compared to the standard arm $(p<0.001$ and $p=0.03$, respectively). The data from this trial do not support the substitution of cytarabine by azacitidine in intensive induction therapy.
\end{abstract}

\section{Introduction}

Acute myeloid leukemia (AML) is predominantly a disease of older patients for whom prognosis remains poor [1, 2]. Intensive chemotherapy, usually consisting of an anthracycline and cytarabine, induces remission in about $50 \%$ of older fit patients, but most patients relapse and succumb to their disease. Beyond patient-associated factors, such as increasing age, comorbidities and poor performance status, disease-related factors and particularly an unfavorable

Presented in part at the 56th Congress of the American Society of Hematology, 2012.

R. F. Schlenk

richard.schlenk@nct-heidelberg.de

Extended author information available on the last page of the article genetic profile of the disease predicts resistance to current standard therapy [3, 4]. In line, the proportion of patients with an unfavorable disease profile such as intermediate-2 and high risk according to 2010 European LeukemiaNet (ELN) [5] recommendations increases with older age from about one third in patients below the age of 60 years to nearly $60 \%$ in patients 70 years or older [6].

Epigenetic changes, such as mutations of epigenetic modifiers and aberrant DNA methylation, are frequent in AML [7, 8]. Furthermore, DNA methylation has emerged as an attractive therapy target in AML $[9,10]$ and particularly in patients with unfavorable cytogenetic and/or a TP53 mutation [11, 12]. The high failure rate of intensive induction therapy in AML with an unfavorable genetic profile may be a result of cytarabine resistance [13]. In contrast, patients with a favorable genetic profile such as core-binding factor (CBF) AML or AML with mutated NPM1 are sensitive to standard induction therapy [3, 4]. The improved understanding of the molecular pathogenesis 
has spurred new treatment strategies targeting specific molecular defects. So far, this concept has been successful by using all-trans retinoic acid (ATRA) and/or arsenic trioxide in the therapy of acute promyelocytic leukemia (APL) [14], as well as by introducing midostaurin and enasidenib in the therapy of AML with FLT3 and IDH2 mutations, respectively $[15,16]$.

In this trial, patients with CBF-AML [17], AML with mutated NPMI [18], and AML with FLT3 internal tandem duplication (ITD) [19] were excluded due to competitive trials that were active during the same time resulting in a selection of patients with more high-risk disease features. The hypothesis was that these patients may particularly benefit from incorporation of the hypomethylating agent azacitidine in induction therapy. Thus, the aim of our study was to evaluate the impact of substituting cytarabine by azacitidine administered sequentially or concurrently with idarubicin and etoposide on response rate and survival endpoints. The AMLSG 12-09 trial was a prospective, randomized, multi-institutional, controlled phase-II trial.

\section{Patients and methods}

\section{Patients}

Between October 2010 and March 2012, 277 adult patients 18-82 years of age with newly diagnosed AML were enrolled; diagnoses included de novo AML, secondary AML with a preceding history of myelodysplastic syndrome or myeloproliferative neoplasm (s-AML), and therapy-related AML following treatment of a primary malignancy (t-AML), as defined by the WHO 2008 classification [20]. Excluded were APL, CBF-AML, AML with FLT3-ITD, and AML with NPM1 mutation; further exclusion criteria were concomitant renal (creatinine $>1.5 \mathrm{x}$ upper normal serum level), liver (AST or ALP $>2.5 \mathrm{x}$ upper normal serum level) or cardiac dysfunction (New York Heart Association III/IV), uncontrolled infectious disease, primary coagulation disturbance or ECOG performance status $>2$. Written informed consent was obtained from all patients. The protocol was approved by the lead Ethics Committee and registered at clinicaltrialsregister.eu (EudraCT Number: 2009-016142-44) and clinicaltrials.gov (ClinicalTrials.gov Identifier: NCT01180322).

\section{Cyto- and molecular genetics}

Chromosome banding analysis was performed centrally in the two AMLSG Laboratories for Cytogenetics (Hannover, Ulm). Karyotypes were designated according to the International System for Human Cytogenetic Nomenclature [21]. Leukemia samples were analyzed for mutations in FLT3 (ITDs and tyrosine kinase domain [TKD] mutations at codons D835/ I836), CEBPA, NPM1, IDH1/2, RUNX1, ASXL1, TP53, and $D N M T 3 A$ as previously described [22-27].

\section{Study design}

Patients were randomized into 4 arms in a 1:1:1:1 manner. Induction therapy regimens comprised: a) STANDARD, cytarabine $100 \mathrm{mg} / \mathrm{m}^{2} /$ day by continuous intravenous (iv) infusion on days $1-7$, idarubicin $12 \mathrm{mg} / \mathrm{m}^{2} /$ day by iv push on days $1,3,5$ (application in patients $>65$ years at days $1+$ 3 only), etoposide $100 \mathrm{mg} / \mathrm{m}^{2} /$ day by 1 -hour iv infusion on days 1,2,3 (application in patients $>65$ years at days $1+3$ only); b) Azacitidine PRIOR, azacitidine $100 \mathrm{mg} / \mathrm{m}^{2} /$ day by subcutaneous (sc) injection on days -5 to day -1 , idarubicin and etoposide as in STANDARD; c) Azacitidine CONCURRENT, azacitidine $100 \mathrm{mg} / \mathrm{m}^{2} /$ day by sc injection on days 1-5 concurrently to idarubicin and etoposide as in STANDARD; d) Azacitidine AFTER, azacitidine $100 \mathrm{mg} /$ $\mathrm{m}^{2}$ per day by sc injection on days $4-8$. Patients in complete remission (CR), CR with incomplete hematological recovery (CRi) or partial remission (PR) after first induction therapy received a second cycle with a dose reduction of idarubicin (administered on days $1+3$ only).

\section{Consolidation therapy}

Patients in CR/CRi following induction therapy were assigned to consolidation therapy with either allogeneic hematopoieticcell transplantation (HCT) from a matched related or unrelated donor (one consolidation cycle before allogeneic HCT was optional), or, in second priority, three cycles of high-dose cytarabine (HiDAC). Cytarabine was administered by iv infusion in a dose of $3 \mathrm{~g} / \mathrm{m}^{2}$ bid on days 1,2,3 [28]. For patients > 65 years of age, dose of cytarabine was reduced to $1 \mathrm{~g} / \mathrm{m}^{2}$. Lenograstim $\left(34 \times 10^{6} \mathrm{IU} / \mathrm{ml}\right)$ was applied sc daily beginning on day 10 until neutrophil count $>0.5 \times 10^{9} / 1$.

\section{Maintenance therapy}

with azacitidine was intended in all patients who were randomized to one of the azacitidine-containing induction therapy arms. Maintenance therapy was scheduled for a total duration of 2 years. Azacitidine was administered in a dose of $50 \mathrm{mg} / \mathrm{m}^{2}$ per day by sc injection on days $1-5$ every 4 weeks.

\section{Definition of response criteria, survival endpoints and hematologic recovery}

In accordance with standard criteria, $\mathrm{CR}$ was defined as $<$ $5 \%$ bone marrow blasts, an absolute neutrophil count of $\geq$ $1.0 \mathrm{G} / \mathrm{L}$, a platelet count of $\geq 100 \mathrm{G} / \mathrm{L}$, no blasts in the peripheral blood and no extramedullary leukemia; CR with 


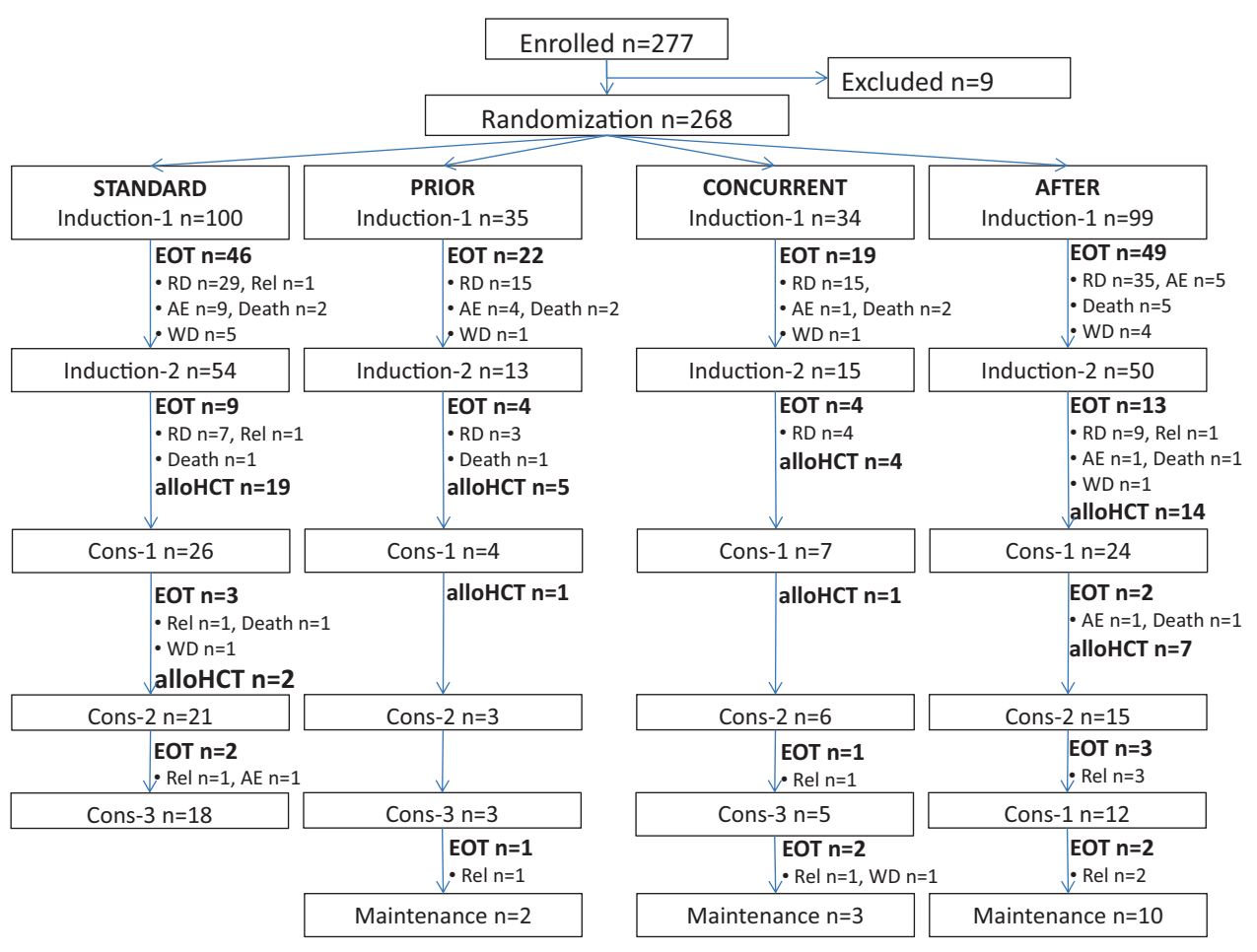

Fig. 1 CONSORT Diagram. Abbreviations: STANDARD, Cytarabine $100 \mathrm{mg} / \mathrm{m}^{2} /$ day by continuous iv infusion on days $1-7$, idarubicin 12 $\mathrm{mg} / \mathrm{m}^{2} /$ day by iv push on days $1,3,5$ (application in patients $>65$ years at days $1+3$ only), etoposide $100 \mathrm{mg} / \mathrm{m}^{2} /$ day by 1 -hour iv infusion on days $1,2,3$ (application in patients $>65$ yrs at days $1+3$ only); PRIOR, Azacitidine $100 \mathrm{mg} / \mathrm{m}^{2}$ per day by subcutaneous injection on days -5 to day -1 , idarubicin and etoposide as in STANDARD; CONCURRENT,

incomplete blood count recovery (CRi) was characterized as $\mathrm{CR}$ except for residual neutropenia (neutrophils $<1.0 \mathrm{G} / \mathrm{L}$ ) or thrombocytopenia (platelets $<100 \mathrm{G} / \mathrm{L}$ ) [5]. Relapse was defined as $>5 \%$ bone marrow blasts or new extramedullary leukemia in patients with previously documented CR/CRi.

Event-free survival (EFS), relapse-free survival (RFS) and overall survival (OS) were defined as recommended [5]. Times to leukocyte, neutrophil and platelet recovery were measured from the first day of chemotherapy of each cycle until the first day with values $\geq 1, \geq 0.5$ and $\geq 20 \mathrm{G} / \mathrm{L}$ for white blood cells (WBC), neutrophils and platelets, respectively. Toxicities were defined and graded according to the National Cancer Institute (NCI) Common Toxicity Criteria, version 3.0.

\section{Sample size planning and statistical analysis}

An optimal two-stage design of Simon was used to evaluate each arm of the study separately [29]. The null hypothesis in each arm was $\mathrm{H}_{0}: \pi \leq 0.40$, whereby $\pi$ denoted the true $\mathrm{CR} / \mathrm{CRi}$ rate of the induction therapy. In contrast, an effective therapy was estimated to achieve at least a CR/CRi rate of $55 \%$. The sample size was calculated to detect an effective therapy with a power of $80 \%$. The level of significance was fixed at $\alpha=5 \%$ for each treatment arm. Based

Azacitidine $100 \mathrm{mg} / \mathrm{m}^{2} /$ day by sc injection on days $1-5$, idarubicin and etoposide as in STANDARD; AFTER, Azacitidine $100 \mathrm{mg} / \mathrm{m}^{2}$ per day by sc injection days 4-8, idarubicin and etoposide as in STANDARD; EOT, end of trial; RD, refractory disease; Rel, relapse; AE, adverse event; WD, withdrawal; alloHCT, allogeneic hematopoietic-cell transplantation; Cons, consolidation

on the assumptions an efficacy of the corresponding therapy was rejected in the first stage of 26 treated patients, if 11 or less patients achieved a CR/CRi. If 12 or more patients achieved a $\mathrm{CR} / \mathrm{CRi}$ during this first stage, the trial proceeded to second stage with a total sample size of 84 patients per treatment arm. Randomization after completion of the first stage was carried on until first stage results were available. Second stage rejection was considered if not more than 40 patients achieved a CR/CRi.

Pairwise comparisons between patient subgroups were performed by the Mann-Whitney or Kruskal-Wallis test for continuous variables and by Fisher's exact test for categorical variables. Univariable and multivariable logistic regression models were applied to investigate the influence of covariates (age, sex, CEBPA, DNMT3A, RUNX1, ASXL1, $I D H 1, I D H 2, T P 53$, ELN high-risk category) on response to induction therapy. Secondary endpoints of the study were OS, RFS, EFS, therapy-related toxicity and their correlation with the study drug. The median duration of follow-up was calculated by the reverse Kaplan-Meier estimate [30]; the Kaplan-Meier method was used to estimate the distributions of EFS, RFS and OS. Survival distributions were compared using the log-rank test. Multivariable AndersenGill regression models were used to evaluate the same 
Table 1 Patient and disease characteristics according to randomization

\begin{tabular}{|c|c|c|c|c|c|c|}
\hline & $\begin{array}{l}\text { All patients } \\
(n=268)\end{array}$ & $\begin{array}{l}\text { STANDARD } \\
(n=100)\end{array}$ & $\begin{array}{l}\text { PRIOR } \\
(n=35)\end{array}$ & $\begin{array}{l}\text { CONCURRENT } \\
(n=34)\end{array}$ & $\begin{array}{l}\text { AFTER } \\
(n=99)\end{array}$ & $p$ value \\
\hline Age in years Median (Range) & $62.6(18-83)$ & $62.6(20-81)$ & $63.5(21-79))$ & $63.6(36-83)$ & $62.3(18-79)$ & 0.73 \\
\hline \multicolumn{7}{|l|}{ ECOG Performance Status } \\
\hline 0, No. $(\%)$ & $113(42)$ & $42(42)$ & $16(46)$ & $13(38)$ & $42(42)$ & \multirow[t]{2}{*}{0.94} \\
\hline $1-2$, No. $(\%)$ & $155(58)$ & $58(58)$ & $19(54)$ & $21(62)$ & $57(58)$ & \\
\hline Male sex, No. (\%) & $144(54)$ & $49(49)$ & $21(60)$ & $14(41)$ & $60(61)$ & 0.14 \\
\hline Missing & 6 & 2 & 0 & 2 & 2 & \\
\hline \multicolumn{7}{|l|}{$\mathrm{WBC}, 10^{9} / \mathrm{L}(n=262)$} \\
\hline Median (Range) & $3.7(0.3-214)$ & $3.0(0.4-186)$ & $3.4(0.8-155)$ & $3.6(0.6-141)$ & $4.2(0.3-214)$ & 0.78 \\
\hline \multicolumn{7}{|l|}{ Hemoglobin, g/dL $(n=262)$} \\
\hline Median (Range) & $9.2(5.2-13.8)$ & $9.1(5.2-12.9)$ & $9.8(5.9-12.9)$ & $9.6(6.9-13.6)$ & $9.1(5.6-13.8)$ & 0.33 \\
\hline \multicolumn{7}{|l|}{ Platelets, $10^{9} / \mathrm{L}(n=262)$} \\
\hline Median (Range) & $63.5(3-1286)$ & $64.5(3-419)$ & $61(16-1286)$ & $53(12-301)$ & $67(4-956)$ & 0.77 \\
\hline \multicolumn{7}{|l|}{ a Bone marrow blasts, $\%(n=252)$} \\
\hline Median (Range) & $60(0-100)$ & $53(0-100)$ & $63.5(10-100)$ & $61.5(20-93)$ & $60(0-99)$ & 0.84 \\
\hline \multicolumn{7}{|l|}{ Peripheral blood blasts, $\%(n=246)^{\mathrm{a}}$} \\
\hline Median (Range) & $10(0-97)$ & $12(0-97)$ & $16(0-88)$ & $5(0-92)$ & $8.5(0-97) 9$ & 0.95 \\
\hline \multicolumn{7}{|l|}{ Cytogenetics $(n=230)$} \\
\hline Normal karyotype, $n(\%)$ & $93(40)$ & $38(45)$ & $10(30)$ & $11(44)$ & $34(39)$ & 0.69 \\
\hline $\operatorname{inv}(3) / \mathrm{t}(3 ; 3), n(\%)$ & $5(2)$ & $2(2)$ & $3(9)$ & $0(0)$ & $0(0)$ & 0.02 \\
\hline $\mathrm{t}(11 \mathrm{q} 23 ; \mathrm{var}), n(\%)$ & $11(5)$ & $6(7)$ & $1(3)$ & $1(4)$ & $3(3)$ & 0.79 \\
\hline $\begin{array}{l}\text { Myelodysplasia-related } \\
\text { karyotype, n }(\%)^{\mathrm{b}}\end{array}$ & $72(33)$ & $27(34)$ & $10(32)$ & $5(21)$ & $30(35)$ & 0.55 \\
\hline Complex, $n(\%)^{\mathrm{b}}$ & $46(20)$ & $15(18)$ & $5(15)$ & $520)$ & $21(24)$ & 0.61 \\
\hline Monosomal, $n(\%)^{\mathrm{b}}$ & $32(15)$ & $10(13)$ & $4(13)$ & $2(8)$ & $16(19)$ & 0.69 \\
\hline \multicolumn{7}{|l|}{ AML type $(n=268)$} \\
\hline de novo AML, $n(\%)$ & $197(74)$ & $73(73)$ & $24(69)$ & $24(71)$ & $76(77)$ & 0.68 \\
\hline s-AML, $n(\%)$ & $50(19)$ & $16(16)$ & $8(23)$ & $8(24)$ & $18(18)$ & \\
\hline $\mathrm{t}-\mathrm{AML}, n(\%)$ & $21(8)$ & $11(11)$ & $3(9)$ & $2(6)$ & $5(5)$ & \\
\hline \multicolumn{7}{|l|}{ Mutated $C E B P A(n=238)$} \\
\hline Single mutant $\mathrm{n}(\%)$ & $6(3)$ & $4(4)$ & $0(0)$ & $0(0)$ & $2(2)$ & 0.81 \\
\hline Double mutant, n (\%) & $17(7)$ & $7(8)$ & $1(3)$ & $1(3)$ & $8(9)$ & \\
\hline Mutated DNMT3A, $n(\%)(n=235)$ & $40(17)$ & $17(18)$ & $6(21)$ & $6(20)$ & $11(13)$ & 0.66 \\
\hline Mutated ASXL1, $n(\%)(n=213)$ & $32(15)$ & $16(20)$ & $5(19)$ & $2(7)$ & $9(12)$ & 0.34 \\
\hline Mutated RUNXI, $n(\%)(n=233)$ & $46(20)$ & $15(16)$ & $8(30)$ & $9(30)$ & $14(17)$ & 0.17 \\
\hline Mutated IDHI, $n(\%)(n=231)$ & $25(11)$ & $13(14)$ & $3(11)$ & $3(10)$ & $6(7)$ & 0.53 \\
\hline Mutated $I D H 2, n(\%)(n=233)$ & $32(14)$ & $16(17)$ & $5(19)$ & $4(13)$ & $7(8)$ & 0.23 \\
\hline Mutated TP53, $n(\%)(n=215)$ & $27(13)$ & $5(6)$ & $3(11)$ & $6(21)$ & $13(17)$ & 0.08 \\
\hline
\end{tabular}

STANDARD cytarabine $100 \mathrm{mg} / \mathrm{m}^{2} /$ day by continuous iv infusion on days $1-7$, idarubicin $12 \mathrm{mg} / \mathrm{m}^{2} /$ day by iv push on days $1,3,5$ (application in patients $>65$ years at days $1+3$ only), etoposide $100 \mathrm{mg} / \mathrm{m}^{2} /$ day by 1 -hour iv infusion on days $1,2,3$ (application in patients $>65$ years at days $1+$ 3 only), PRIOR azacitidine $100 \mathrm{mg} / \mathrm{m}^{2} /$ day by subcutaneous injection on days -5 to day -1 , idarubicin and etoposide as in STANDARD, CONCURRENT azacitidine $100 \mathrm{mg} / \mathrm{m}^{2}$ per day by sc injection on days $1-5$, idarubicin and etoposide as in STANDARD, AFTER Azacitidine 100 $\mathrm{mg} / \mathrm{m}^{2} /$ day by sc injection days 4-8, idarubicin and etoposide as in STANDARD, ECOG Eastern Cooperative Oncology Group, WBC white blood cells, $s$-AML AML after previous myelodysplastic syndrome or myeloproliferative neoplasm, $t$-AML therapy-related AML, $C E B P A, C C A A T /$ enhancer-binding protein alpha, DNMT3A DNA methyltransferase 3A, ASXL1 additional sex combs like 1, RUNX1 runt-related transcription factor 1, IDH Isocitrate dehydrogenase, TP53 tumor protein P53

an case of bone marrow blasts $<20 \%$, diagnosis of AML was established based on extramedullary disease or peripheral blood blasts $>20 \%$ batients can be listed in more than one of these overlapping categories

prognostic variables as for response to induction therapy as well as alloHCT as a time-dependent covariable [31]. Missing data were replaced by 50 imputations using multivariate imputations by chained equations applying predictive mean matching [32]. Backward selection applying a stopping rule based on a p-value of 0.50 was used in multivariable regression models to exclude redundant or unnecessary variables [32].

All statistical analyses were performed with the statistical software environment $R$, version 3.2.1, using the $\mathrm{R}$ packages rms, version 4.3-1, and cmprsk, version 2.2-2 [33]. 


\section{Results}

\section{Patients and baseline characteristics}

Of 277 patients, $9(3 \%)$ were excluded due to violation of inclusion/exclusion criteria: no diagnosis of AML, $n=3$; AML with NPM1 mutation, $n=1$; presence of Philadelphia chromosome, $n=1$; organ insufficiency (renal failure), $n=$ 1 ; withdrawal of informed consent, $n=2$; other reason (extramedullary manifestation of AML in spleen), $n=1$. Thus, overall 268 patients were randomized (Fig. 1).

On the basis of the two-stage design of the study, initially 104 patients were randomized in the first stage between October 2010 and September 2011 with equal distribution into the 4 arms ( $n=26$ each). The baseline characteristics of all randomized patients as well as those randomized during the first stage (data not shown) were equally distributed except for the frequency of inv(3)/t( $3 ; 3)$ (Table 1).

\section{Induction therapy}

Of 104 patients treated during the first stage of the study, 49 (47\%) achieved CR/CRi, 49 (47\%) had refractory disease (RD), and $6(6 \%)$ died. The number of patients achieving $\mathrm{CR} / \mathrm{CRi}$ in the treatment arms PRIOR and CONCURRENT were 11 and 10, respectively. Therefore, both arms were stopped with the effective date 16 September 2011. The treatment arms STANDARD and AFTER were continued based on 14 patients achieving CR/CRi each. After recruitment of 168 patients in treatment arms STANDARD and AFTER, 45/84 (54\%) and 37/84 (44\%) patients achieved CR/CRi, respectively. Thus, only the STANDARD arm of the study was identified as effective according to the predefined criteria.

Overall, 268 patients received induction therapy, 126 (47\%) patients achieved CR/CRi, 130 (49\%) had RD, and $12(4 \%)$ died during induction therapy. When salvage therapy outside the protocol was taken into account, CR/ CRi was achieved in 161 patients (60\%), 93 patients had RD (35\%), and 14 died (5\%), with all treatment arms showing similar increases in response.

A logistic regression model revealed biallelic CEBPA mutation as favorable (Odds Ratio [OR], 7.35; 95\%-Confidence Interval [CI], 1.43-27.3), and adverse risk according to 2010 ELN risk classification as unfavorable (OR, 0.48 ; 95\%-CI, 0.26-0.87) parameters for CR/CRi achievement. Within the final model, the estimates for the treatment arms containing azacytidine compared to STANDARD were as follows (PRIOR; OR, 0.59; 95\%-CI, 0.25-1.37; CONCURRENT, OR, 0.44; 95\%-CI, 0.19-1.05; AFTER, OR, 0.71; 95\%-CI, 0.39-1.30).

We also explored the impact of genetics as predictive factor for the treatment effect on response. Patients with
IDH2-mutated AML had a higher CR/CRi rate with STANDARD than with azacitidine-containing regimens (8/16 [50\%] and 1/16 [6\%], $p=0.02$, respectively); similarly, CR/ CRi rate in patients with RUNXI-mutated AML was in trend superior in STANDARD $(10 / 15,66 \%)$ compared to azacitidine-regimens $(11 / 3135 \%, p=0.06)$. Twenty-seven patients had AML with TP53 mutation, 13 patients were treated in AFTER and achieved a CR/CRi rate of $46 \%$, whereas CR/CRi rate in the remaining patients was only $21 \%$ $(p=0.23)$. In patients with monosomal, complex ( $\geq 3$ aberrations), or myelodysplasia-related karyotypes there was no difference in CR/CRi rates between STANDARD compared to all other arms ( $p=0.66, p=0.99, p=0.46$, respectively).

No differences in adverse events were observed in the four treatment arms except laboratory abnormalities all grades being more frequent in STANDARD and CONCURRENT as well as vascular abnormalities all grades and grade $\geq 3$ predominantly observed in PRIOR (Table 2 ).

\section{Consolidation therapy}

Consolidation with HiDAC was administered for one cycle in 61 patients, for two cycles in 45 patients, and for three cycles in 37 patients. Within the protocol, 49 patients proceeded to allogeneic $\mathrm{HCT}$ in first $\mathrm{CR} / \mathrm{CRi}$; overall, 88 patients received allogeneic $\mathrm{HCT}$ in first CR/CRi, 45 patients with $\mathrm{RD}$, and 21 patients after relapse. Forty-six patient received a matchedrelated donor transplant, 107 a matched-unrelated, and one patient a transplant from a haploidentical donor.

\section{Maintenance therapy}

Maintenance therapy with azacitidine was started in 15 patients. Median number of applied cycles was 5 (range, 1-24), with 2 patients receiving the intended 24 cycles. In 13 patients maintenance was terminated early (relapse, $n=12$; toxicity, $n=1$ ).

\section{Survival analysis}

Median follow-up was 56 months (95\%-CI, 54-57 months). Overall median and 4-year EFS, RFS, and OS were 3.5 months, 15 months, 16 months, and $16 \%$ (95\%-CI, $12-21 \%$ ), 30\% (95\%-CI, 23-39 months), $29 \%$ (95\%-CI, 24-35\%), respectively. EFS (Fig. 2a) was significantly different among the four arms $(p=0.008)$, with inferior EFS in all three azacitidine arms compared to STANDARD ( $p<0.001$ ). RFS and OS (Fig. 2b, c) were not significantly different among the four study arms $(p=0.18, p=0.12$; respectively), but inferior when the three azacitidine arms were compared to STANDARD $(p=0.04, p=0.03$; respectively). Even in patients proceeding to an allogeneic $\mathrm{HCT}$ in first CR/CRi, RFS was in trend inferior in the three 
Table 2 Adverse Event occurring in first induction therapy according to treatment arm and CTCAE category

\begin{tabular}{|c|c|c|c|c|c|c|c|c|c|}
\hline & $\begin{array}{l}\text { STANDARD } \\
(\mathrm{n}=100) \\
<\text { grade } 3\end{array}$ & $\geq$ grade 3 & $\begin{array}{l}\text { Prior } \\
(\mathrm{n}=35) \\
<\text { grade } 3\end{array}$ & $\geq$ grade 3 & $\begin{array}{l}\text { CONCURRENT } \\
(\mathrm{n}=34) \\
<\text { grade } 3\end{array}$ & $\geq$ grade 3 & $\begin{array}{l}\text { AFTER } \\
(\mathrm{n}=99) \\
<\text { grade } 3\end{array}$ & $\geq$ grade 3 & $\begin{array}{l}\text { p-value } \\
\text { "all grades } \\
* \geq \text { grade } 3\end{array}$ \\
\hline $\begin{array}{l}\text { Allergy/ } \\
\text { Immunology }\end{array}$ & 13 (13) & $1(1)^{*}$ & $5(14)$ & $1(3)^{*}$ & $3(9)$ & $0(0)^{*}$ & $15(15)$ & $1(1)^{*}$ & $\begin{array}{l}0.75^{\prime} \\
0.69^{*}\end{array}$ \\
\hline Cardiac Arrhythmia & $3(3)$ & $3(3)$ & $1(3)$ & $1(3)$ & $3(9)$ & $2(6)$ & $6(6)$ & $5(5)$ & $\begin{array}{l}0.33^{\prime} \\
0.81^{*}\end{array}$ \\
\hline Cardiac General & $14(14)$ & $9(9)$ & $7(20)$ & $2(6)$ & $6(18)$ & $2(6)$ & $9(9)$ & $8(8)$ & $\begin{array}{l}0.61 \\
0.97 *\end{array}$ \\
\hline Coagulation & $9(9)$ & $1(1)$ & $3(9)$ & $0(0)$ & $4(12)$ & $0(0)$ & $9(9)$ & $1(1)$ & $\begin{array}{l}0.97 \\
0.99 *\end{array}$ \\
\hline $\begin{array}{l}\text { Constitutional } \\
\text { Symptoms }\end{array}$ & $53(53)$ & $7(7)$ & $16(46)$ & $1(3)$ & $14(41)$ & $2(6)$ & $49(49)$ & $3(3)$ & $\begin{array}{l}0.46^{\prime} \\
0.61 *\end{array}$ \\
\hline Dermatology/Skin & $42(42)$ & $3(3)$ & $10(29)$ & $1(3)$ & $16(47)$ & $0(0)$ & $33(33)$ & $7(7)$ & $\begin{array}{l}0.49^{\prime} \\
0.31^{*}\end{array}$ \\
\hline Endocrine & $4(4)$ & $0(0)$ & $0(0)$ & $0(0)$ & $0(0)$ & $2(6)$ & $4(4)$ & $0(0)$ & $\begin{array}{l}0.66 \\
0.02 *\end{array}$ \\
\hline Gastrointestinal & $58(58)$ & $23(23)$ & $24(69)$ & $5(14)$ & $24(71)$ & $4(12)$ & $60(61)$ & $20(20)$ & $\begin{array}{l}0.99^{\prime} \\
0.48^{*}\end{array}$ \\
\hline $\begin{array}{l}\text { Hemorrhage/ } \\
\text { Bleeding }\end{array}$ & $25(25)$ & $6(6)$ & $6(17)$ & $2(6)$ & $9(26)$ & $3(9)$ & $28(28)$ & $5(5)$ & $\begin{array}{l}0.66^{\prime} \\
0.85^{*}\end{array}$ \\
\hline $\begin{array}{l}\text { Hepatobiliary/ } \\
\text { Pancreas }\end{array}$ & $0(0)$ & $2(2)$ & $1(3)$ & $0(0)$ & $0(0)$ & $1(3)$ & $0(0)$ & $2(2)$ & $\begin{array}{l}0.99^{\prime} \\
0.92^{*}\end{array}$ \\
\hline Infection & $5(5)$ & $75(75)$ & $6(17)$ & $23(66)$ & $4(12)$ & $24(71)$ & $17(17)$ & $64(65)$ & $\begin{array}{l}0.99 \\
0.42 *\end{array}$ \\
\hline Lymphatics & $3(3)$ & $0(0)$ & $0(0)$ & $0(0)$ & $1(3)$ & $0(0)$ & $5(5)$ & $0(0)$ & $\begin{array}{l}0.68 \\
0.99 *\end{array}$ \\
\hline $\begin{array}{l}\text { Metabolic/ } \\
\text { Laboratory }\end{array}$ & $45(45)$ & $16(16)$ & $8(23)$ & $5(14)$ & $14(41)$ & $5(15)$ & $25(25)$ & $14(14)$ & $\begin{array}{l}0.007 \\
0.99 *\end{array}$ \\
\hline $\begin{array}{l}\text { Musculoskeletal/ } \\
\text { Soft Tissue }\end{array}$ & $2(2)$ & $4(4)$ & $3(9)$ & $0(0)$ & $0(0)$ & $0(0)$ & $8(8)$ & $2(2)$ & $\begin{array}{l}0.22 \\
0.48^{*}\end{array}$ \\
\hline Neurology & 27 (27) & $1(1)$ & $10(29)$ & $1(3)$ & $9(26)$ & $2(6)$ & $28(28)$ & $1(1)$ & $\begin{array}{l}0.95 \\
0.22 *\end{array}$ \\
\hline Ocular/Visual & $4(4)$ & $1(1)$ & $1(3)$ & $0(0)$ & $3(9)$ & $0(0)$ & $8(8)$ & $1(1)$ & $\begin{array}{l}0.52 \\
0.99 *\end{array}$ \\
\hline Pain & $50(50)$ & $6(6)$ & $18(51)$ & $2(6)$ & $17(50)$ & $2(6)$ & $48(48)$ & $5(5)$ & $\begin{array}{l}0.98 \\
0.99 *\end{array}$ \\
\hline $\begin{array}{l}\text { Pulmonary/Upper } \\
\text { Respiratory }\end{array}$ & $20(20)$ & $5(5)$ & $4(11)$ & $6(17)$ & $7(21)$ & $3(9)$ & $24(24)$ & $6(6)$ & $\begin{array}{l}0.80^{\prime} \\
0.12^{*}\end{array}$ \\
\hline $\begin{array}{l}\text { Renal/ } \\
\text { Genitourinary }\end{array}$ & $43(43)$ & $2(2)$ & $7(20)$ & $1(3)$ & $13(38)$ & $3(9)$ & $31(31)$ & $5(5)$ & $\begin{array}{l}0.09^{\prime} \\
0.25^{*}\end{array}$ \\
\hline $\begin{array}{l}\text { Sexual/ } \\
\text { Reproductive } \\
\text { Function }\end{array}$ & $1(1)$ & $0(0)$ & $1(3)$ & $0(0)$ & $0(0)$ & $0(0)$ & $0(0)$ & $0(0)$ & $\begin{array}{l}0.45^{\prime} \\
0.99 *\end{array}$ \\
\hline Syndromes & $2(2)$ & $0(0)$ & $0(0)$ & $1(3)$ & $0(0)$ & $1(3)$ & $1(1)$ & $1(1)$ & $\begin{array}{l}0.99^{\prime} \\
0.13^{*}\end{array}$ \\
\hline
\end{tabular}

CTCAE common terminology criteria for adverse Events, STANDARD cytarabine $100 \mathrm{mg} / \mathrm{m}^{2} /$ day by continuous iv infusion on days $1-7$, idarubicin $12 \mathrm{mg} / \mathrm{m}^{2} /$ day by iv push on days $1,3,5$ (application in older patients ( $>65$ years) at days $1+3 \mathrm{only}$ ), etoposide $100 \mathrm{mg} / \mathrm{m}^{2} / \mathrm{day}$ by 1-hour iv infusion on days 1,2,3 (application in older patients at days $1+3$ only), PRIOR azacitidine $100 \mathrm{mg} / \mathrm{m}^{2} / \mathrm{day}$ by subcutaneous injection on days -5 to day -1 , idarubicin and etoposide as in STANDARD, CONCURRENT azacitidine $100 \mathrm{mg} / \mathrm{m}^{2} /$ day by sc injection on days $1-5$ before idarubicin and etoposide, Idarubicin and etoposide as in STANDARD, AFTER azacitidine $100 \mathrm{mg} / \mathrm{m}^{2} /$ day by sc injection days 4-8, idarubicin and etoposide as in STANDARD

azacitidine arms compared to STANDARD $(p=0.07)$. In an Anderson Gill regression model including allogeneic $\mathrm{HCT}$ performed in first $\mathrm{CR} / \mathrm{CRi}$ as a time-dependent covariable, all azacitidine arms showed worse outcome; further unfavorable factors were higher age, male sex, presence of a TP-53 mutation, and ELN high-risk. 

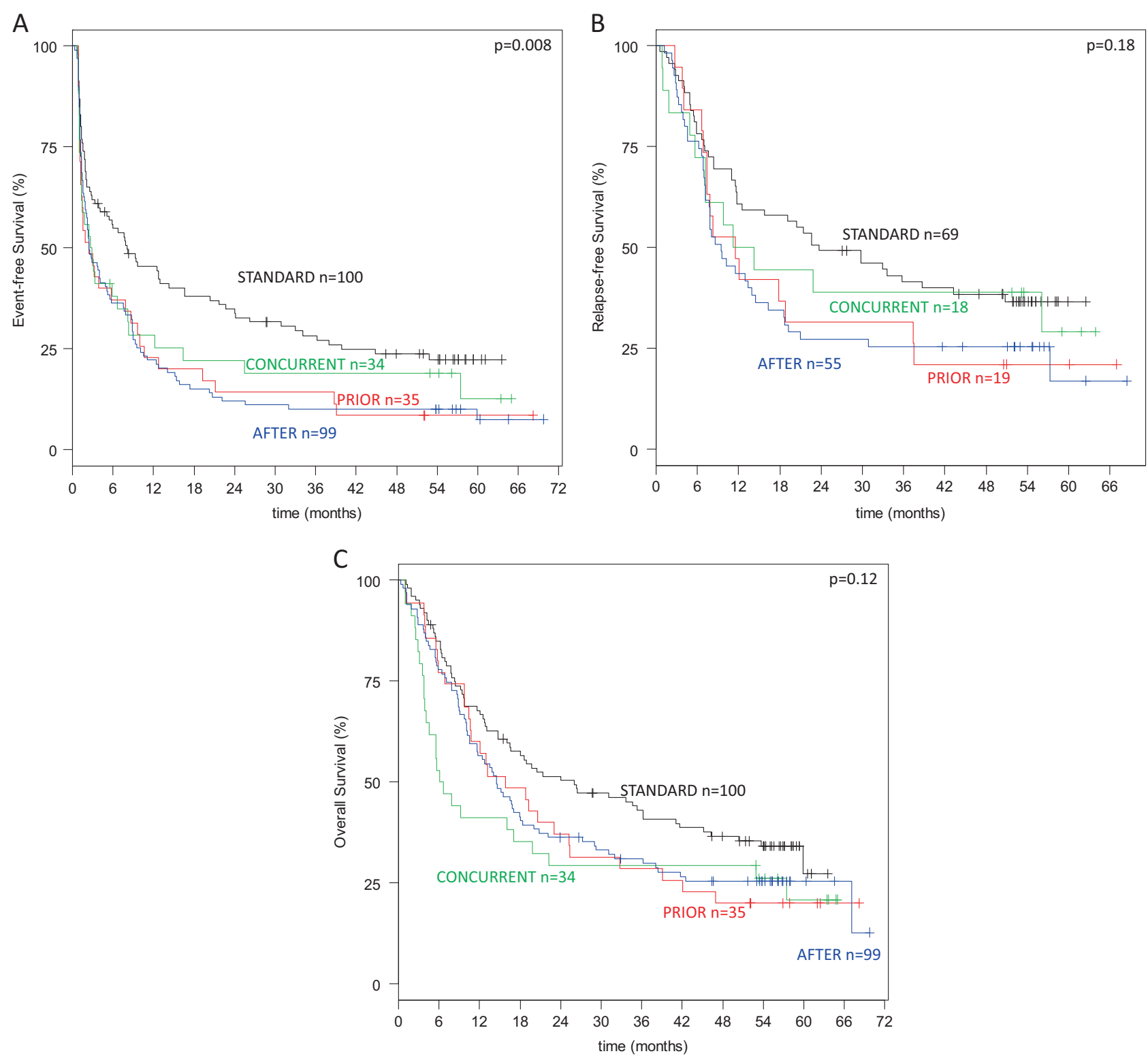

Fig. 2 Kaplan-Meier plots illustrating the influence of upfront randomization on event-free (EFS) (a), relapse-free (RFS) (b), and overall survival (OS) (c)

Favorable factors were biallelic CEBPA mutations, female gender, and allogeneic HCT in first CR/CRi (Table 3).

\section{Discussion}

Based on the improved understanding of the molecular pathogenesis of AML, new treatment strategies targeting specific molecular defects have been implemented within treatment trials of the German-Austrian AML Study Group (AMLSG), such as FLT3 inhibition in AML with FLT3ITD (ClinicalTrials.gov Identifier: NCT01477606) [19], KIT-inhibition in CBF-AML (NCT00850382) [17], and the use of gemtuzumab ozogamicin in AML with NPM1 mutations (NCT00893399, EudraCT 2009-011889-28) [18].

The remaining patients not eligible for these targeted approaches were mainly patients exhibiting an intermediate2 or high-risk according to the 2010 ELN categorization [5]. Furthermore, $20 \%$ of patients had RUNX1-mutated AML, 15\% ASXL1-mutated AML, and 13\% TP53-mutated AML, all markers that are categorized within the adverse-risk group in the 2017 ELN risk stratification [34]; in addition, $25 \%$ of patients had IDHI/IDH2-mutated AML. Based on previous observations that hypomethylating agents may be particularly active in AML with poor-risk disease features, 
Table 3 Anderson-Gill regression model on the endpoint overall survival including allogeneic hematopoietic-cell transplantation performed in first $\mathrm{CR} / \mathrm{CRi}$ as a time-dependent covariable

\begin{tabular}{lccc}
\hline & HR & $95 \%$-CI & $p$ value \\
\hline Treatment Arm & & & \\
$\quad$ PRIOR & 1.58 & $0.95-2.63$ & 0.08 \\
$\quad$ CONCURRENT & 1.84 & $1.02-3.37$ & 0.04 \\
$\quad$ AFTER & 1.49 & $1.00-2.23$ & 0.05 \\
Age (1 year difference) & 1.02 & 1.011 .03 & 0.009 \\
Female sex & 0.69 & 0.490 .98 & 0.04 \\
CEBPA-dm & 0.48 & 0.231 .01 & 0.06 \\
TP53-mut & 2.26 & 1.254 .07 & 0.007 \\
2010 ELN high-risk & 1.67 & 1.102 .53 & 0.02 \\
Allogeneic HCT in first CR/CRi & 0.36 & 0.220 .57 & $<0.0001$ \\
\hline
\end{tabular}

$H C T$ hematopoietic-cell transplantation, $C R$ complete remission, $C R i$ $\mathrm{CR}$ with incomplete blood count recovery, STANDARD cytarabine $100 \mathrm{mg} / \mathrm{m}^{2} /$ day by continuous iv infusion on days $1-7$, idarubicin 12 $\mathrm{mg} / \mathrm{m}^{2} /$ day by iv push on days $1,3,5$ (application in patients $>65$ years at days $1+3$ only), etoposide $100 \mathrm{mg} / \mathrm{m}^{2} /$ day by 1 -hour iv infusion on days 1,2,3 (application in patients $>65$ years at days $1+3$ only), PRIOR azacitidine $100 \mathrm{mg} / \mathrm{m}^{2} /$ day by subcutaneous injection on days -5 to day -1 , idarubicin and etoposide as in STANDARD, CONCURRENT azacitidine $100 \mathrm{mg} / \mathrm{m}^{2} /$ day by sc injection on days 1-5, idarubicin and etoposide as in STANDARD, AFTER azacitidine $100 \mathrm{mg} / \mathrm{m}^{2} /$ day by $\mathrm{sc}$ injection on days $4-8$, idarubicin and etoposide as in STANDARD, CEBPA-dm biallelic CCAAT/enhancer-binding protein alpha mutations, TP53 tumor protein P53, mut mutation, ELN European LeukemiaNet.

such as adverse-risk genetics, myelodysplasia-related changes, or specific gene mutations (e.g., TP53) [10-12, 35-38], our hypothesis was that these patients would benefit from incorporation of azacitidine within a regimen of intensive induction chemotherapy. We opted to substitute cytarabine by azacitidine within the commonly used ICE regimen based on share common chemical and biological characteristics as well as same metabolic pathways of incorporation into DNA. Since different sequences of azacitidine administration may affect efficacy, we employed three different investigational regimens, azacitidine given prior, concomitantly, and after chemotherapy.

On the basis of the optimal two-stage design of Simon, two arms of the study, PRIOR and CONCURRENT, had to be stopped early due to insufficient response rates. The study arm AFTER with azacitidine given after idarubicin and etoposide was similarly effective in the first stage than STANDARD, but in the second stage also failed with inferior induction results. Thus, all three investigational treatment arms were associated with an inferior response rate compared to STANDARD. Although comparable CR/ CRi rates were achieved in all arms if high-dose cytarabinebased salvage therapy was included in the analysis, the inferior initial response in all azacitidine-containing arms translated into inferior EFS, RFS, and OS. Thus, the results of this study suggest that cytarabine remains an important component of induction therapy even in patients with adverse risk. Furthermore, our results are comparable to those reported by Müller-Tidow et al. adding azacitidine prior to intensive induction therapy [39]. In contrast to that study, we did not identify additive toxicity due to azacitidine, probable because of the omission of cytarabine in the azacitidine-containing treatment arms.

In exploratory analyses we looked at the impact of genetics on response to therapy. Of note, in patients exhibiting a complex, monosomal or myelodysplasia-related karyotype there was no beneficial effect of adding azacitidine to intensive induction therapy. Azacitidine was associated with significant inferior response rates in patients with IDH2- and RUNX1-mutated AML. In the AZA-AML001 trial evaluating azacitidine versus conventional care regimens [10], mutations in two genes, that is FLT3 and TET2, were shown to negatively impact OS within the azacitidine treatment arm [12]. Of the 27 patients with TP53-mutated AML in our trial, 13 patients were treated in AFTER and achieved a CR/CRi rate of $46 \%$, whereas CR/ CRi rate in the remaining patients was only $21 \%$, but this difference was not statistically significant $(p=0.23)$. Activity of hypomethylating agents in patients with TP53mutated AML has been demonstrated in two previous trials. In a study of decitabine in patients with AML or MDS, those with TP53 mutations had a $100 \%$ response rate compared with a $41 \%$ response rate in patients with wildtype TP53, however responses were not durable [11]. In the AZA-AML-001 trial, median OS was prolonged by almost 5 months in patients with TP53 mutations receiving azacitidine compared with patients receiving conventional care regimens [12].

In conclusion, in this study of patients with AML exhibiting predominantly higher risk disease features the substitution of cytarabine by azacitidine within an intensive chemotherapy regimen of idarubicin and etoposide failed to improve response rates. On the contrary, two investigational arms had to be stopped early, and all three investigational arms were associated with poorer outcome compared to the standard ICE regimen.

Acknowledgements This work was supported by an unrestricted grant and supply of study drug (azacitidine) from Celgene $\mathrm{GmbH}$. We are also grateful to all members of the German-Austrian AML Study Group (AMLSG) for providing leukemia specimens and clinical data; a list of AMLSG institutions and investigators participating in this study appears in the supplemental Appendix.

Author contribution Conception and Design: RFS, AB, HD. Provision of study materials or patients: RFS, DW, TK, GW HRS, HGD, 
TS, MR, BH, UM, MG, HB, JK, MG, DW, EL, JW, EK, SK, MW, MH, FT, GG, DH, VT, VIG, AB, KD, AG, PP, HD. Collection and assembly of data: RFS, DW. Data analysis and interpretation: RFS, HD, AB. Manuscript writing: RiFS, HD. Final approval of manuscript: RFS, DW, TK, GW, HRS, HGD, TS, MR, BH, UM, MG, HB, JK, MG, DW, EL, JW, EK, SK, MW, MH, FT, GG, DH, VT, VTG, AB, $\mathrm{KD}, \mathrm{AG}, \mathrm{PP}, \mathrm{HD}$.

\section{Compliance with ethical standards}

Conflict of interest $\mathrm{KD}, \mathrm{AK}$, JW and $\mathrm{HD}$ received research funding from Celgene; KD, HD, JW, PP received speakers honoraria from Celgene; KD, PP, JW, AG and HD participated in Celgene Advisory Boards. The other authors declare that they have no conflict of interest.

Publisher's note: Springer Nature remains neutral with regard to jurisdictional claims in published maps and institutional affiliations.

Open Access This article is licensed under a Creative Commons Attribution 4.0 International License, which permits use, sharing, adaptation, distribution and reproduction in any medium or format, as long as you give appropriate credit to the original author(s) and the source, provide a link to the Creative Commons license, and indicate if changes were made. The images or other third party material in this article are included in the article's Creative Commons license, unless indicated otherwise in a credit line to the material. If material is not included in the article's Creative Commons license and your intended use is not permitted by statutory regulation or exceeds the permitted use, you will need to obtain permission directly from the copyright holder. To view a copy of this license, visit http://creativecommons. org/licenses/by/4.0/.

\section{References}

1. Döhner H, Weisdorf DJ, Bloomfield CD. Acute Myeloid Leukemia. N Engl J Med. 2015;373:1136-52.

2. Dombret H, Gardin C. An update of current treatments for adult acute myeloid leukemia. Blood. 2016;127:53-61.

3. Schlenk RF, Döhner H. Genomic applications in the clinic: use in treatment paradigm of acute myeloid leukemia. Hematol Am Soc Hematol Educ Program. 2013;2013:324-30.

4. Bullinger L, Döhner K, Döhner H. Genomics of acute myeloid leukemia diagnosis and pathways. J Clin Oncol. 2017;35:934-46.

5. Döhner H, Estey EH, Amadori S, Appelbaum FR, Büchner T, Burnett AK, et al. Diagnosis and management of acute myeloid leukemia in adults: recommendations from an international expert panel, on behalf of the European LeukemiaNet. Blood. 2010;115:453-74.

6. Nagel G, Weber D, Fromm E, Erhardt S, Lübbert M, Fiedler W, et al. Epidemiological, genetic, and clinical characterization by age of newly diagnosed acute myeloid leukemia based on an academic population-based registry study (AMLSG BiO). Ann Hematol. 2017;96:1993-2003.

7. Papaemmanuil E, Gerstung M, Bullinger L, Gaidzik VI, Paschka P, Roberts ND, et al. Genomic Classification and Prognosis in Acute Myeloid Leukemia. N Engl J Med. 2016;374:2209-21.

8. Metzeler KH, Herold T, Rothenberg-Thurley M, et al. Spectrum and prognostic relevance of driver gene mutations in acute myeloid leukemia. Blood. 2016;128:686-98.

9. Kantarjian HM, Thomas XG, Dmoszynska A, Wierzbowska A, Mazur G, Mayer J, et al. Multicenter, randomized, open-label, phase III trial of decitabine versus patient choice, with physician advice, of either supportive care or low-dose cytarabine for the treatment of older patients with newly diagnosed acute myeloid leukemia. J Clin Oncol. 2012;30:2670-7.

10. Dombret H, Seymour JF, Butrym A, Wierzbowska A, Selleslag D, Jang $\mathrm{JH}$, et al. International phase 3 study of azacitidine vs conventional care regimens in older patients with newly diagnosed AML with $>30 \%$ blasts. Blood. 2015;126:291-9.

11. Welch JS, Petti AA, Miller CA, Fronick CC, O'Laughlin M, Fulton RS, et al. Decitabine in acute myeloid leukemia and myelodysplastic syndromes. N Engl J Med. 2016;375:2023-36.

12. Döhner H, Dolnik A, Tang L, et al. Cytogenetics and gene mutations influence survival in older patients with acute myeloid leukemia treated with azacitidine or conventional care. Leukemia. 2018;32:2546-57.

13. Cros E, Jordheim L, Dumontet C, Galmarini CM. Problems related to resistance to cytarabine in acute myeloid leukemia. Leuk Lymphoma. 2004;45:1123-32.

14. Platzbecker U, Avvisati G, Cicconi L, Thiede C, Paoloni F, Vignetti $\mathrm{M}$, et al. Improved outcomes with retinoic acid and arsenic trioxide compared with retinoic acid and chemotherapy in non-high-risk acute promyelocytic leukemia: final results of the randomized Italian-German APL0406 Trial. J Clin Oncol. 2017;35:605-12.

15. Stone RM, Mandrekar SJ, Sanford BL, Laumann K, Geyer S, Bloomfield CD, et al. Midostaurin plus chemotherapy for acute myeloid leukemia with a FLT3 mutation. $\mathrm{N}$ Engl J Med. 2017;377:454-64.

16. Stein EM, DiNardo CD, Pollyea DA, Fathi AT, Roboz GJ, Altman $\mathrm{JK}$, et al. Enasidenib in mutant $I D H 2$ relapsed or refractory acute myeloid leukemia. Blood. 2017;130:722-31.

17. Paschka P, Schlenk RF, Weber D, Benner A, Bullinger L, Heuser $\mathrm{M}$, et al. Adding dasatinib to intensive treatment in core-binding factor acute myeloid leukemia-results of the AMLSG 11-08 trial. Leukemia. 2018;32:1621-30.

18. Schlenk RF, Paschka P, Krzykalla J, Weber D, Kapp-Schwoerer S, Gaidzik VI. et al. Gemtuzumab Ozogamicin in NPM1-Mutated Acute Myeloid Leukemia (AML): Results from the Prospective Randomized AMLSG 09-09 Phase-III Study. Blood. 2018;132:81 (abstract.

19. Schlenk RF, Weber D, Fiedler W, Salih HR, Wulf G, Salwender $\mathrm{H}$, et al. Midostaurin added to chemotherapy and continued single agent maintenance therapy in acute myeloid leukemia with FLT3ITD. Blood. 2018.

20. Vardiman JW, Thiele J, Arber DA, Brunning RD, Borowitz MJ, Porwit A, et al. The2008 revision of the World Health Organization (WHO) classification of myeloid neoplasms and acute leukemia: rationale and important changes. Blood. 2009;114:937-51.

21. Mitelman F, (ed). ISCN (1995): An international system for human cytogenetic nomenclature. Basel, Switzerland: Karger; 1995.

22. Schlenk RF, Döhner K, Kneba M, Götze K, Hartmann F, Del Valle $\mathrm{F}$, et al. Gene mutations and response to treatment with all-trans retinoic acid in elderly patients with acute myeloid leukemia results from AMLSG Trial AML HD98B. Haematologica. 2009;94:54-60.

23. Schlenk RF, Döhner K, Krauter J, Fröhling S, Corbacioglu A, Bullinger L, et al. Mutations and treatment outcome in cytogenetically normal acute myeloid leukemia. $N$ Engl J Med. 2008;358:1909-18.

24. Paschka P, Schlenk RF, Gaidzik VI, Herzig JK, Aulitzky T, Bullinger L, et al. ASXL1 mutations in younger adult patients with acute myeloid leukemia: a study by the German-Austrian Acute Myeloid Leukemia Study Group. Haematologica. 2015;100:324-30.

25. Rücker FG, Schlenk RF, Bullinger L, Kayser S, Teleanu V, Kett $\mathrm{H}$, et al. TP53 alterations in acute myeloid leukemia with complex 
karyotype correlate with specific copy number alterations, monosomal karyotype, and dismal outcome. Blood. 2012;119:2114-21.

26. Paschka P, Schlenk RF, Gaidzik VI, et al. IDH1 and IDH2 mutations are frequent genetic alterations in acute myeloid leukemia and confer adverse prognosis in cytogenetically normal acute myeloid leukemia with NPM1 mutation without FLT3 internal tandem duplication. J Clin Oncol. 2010;28:3636-43.

27. Gaidzik VI, Teleanu V, Papaemmanuil E, et al. RUNX1 mutations in acute myeloid leukemia are associated with distinct clinicopathologic and genetic features. Leukemia. 2016;30:2160-8.

28. Jaramillo S, Benner A, Krauter J, Martin H, Kindler T, Bentz M, et al. Condensed versus standard schedule of high-dose cytarabine consolidation therapy with pegfilgrastim growth factor support in acute myeloid leukemia. Blood Cancer J. 2017;7:e564.

29. Simon R. Optimal two-stage designs for phase II clinical trials. Control Clin Trials. 1989;10:1-10.

30. Schemper M, Smith TL. A note on quantifying follow-up in studies of failure time. Control Clin Trials. 1996;17:343-6.

31. Andersen P, Gill RD. Cox's regression model for counting processes: a large sample study. Ann Stat. 1982;10:1100-20.

32. Harrell FE. Regression modeling strategies: with applications to linear models, logistic regression, and survival analysis. New York: Springer; 2001.

33. R Development Core Team. R: A language and environment for statistical computing. Vienna: R Foundation for Statistical Computing; 2009. .
34. Döhner H, Estey E, Grimwade D, et al. Diagnosis and management of AML in adults: 2017 ELN recommendations from an international expert panel. Blood. 2017;129:424-47.

35. Lübbert M, Suciu S, Hagemeijer A, Rüter B, Platzbecker U, Giagounidis A, et al. Decitabine improves progression-free survival in older high-risk MDS patients with multiple autosomal monosomies: results of a subgroup analysis of the randomized phase III study 06011 of the EORTC Leukemia Cooperative Group and German MDS Study Group. Ann Hematol. 2016;95:191-9.

36. Pleyer L, Burgstaller S, Girschikofsky M, Linkesch W, Stauder R, Pfeilstocker M, et al. Azacitidine in 302 patients with WHOdefined acute myeloid leukemia: results from the Austrian Azacitidine Registry of the AGMT-Study Group. Ann Hematol. 2014;93:1825-38.

37. Bernal T, Martínez-Camblor P, Sánchez-García J, de Paz R, Luño E, Nomdedeu B, et al. Effectiveness of azacitidine in unselected high-risk myelodysplastic syndromes: results from the Spanish registry. Leukemia. 2015;29:1875-81.

38. Almeida AM, Prebet T, Itzykson R, Ramos F, Al-Ali H, Shammo $\mathrm{J}$, et al. Clinical outcomes of 217 patients with acute erythroleukemia according to treatment type and line: a retrospective multinational study. Int J Mol Sci. 2017;18:E837.

39. Müller-Tidow C, Tschanter P, Röllig C, Thiede C, Koschmieder A, Stelljes M, et al. Azacitidine in combination with intensive induction chemotherapy in older patients with acute myeloid leukemia: The AML-AZA trial of the Study Alliance Leukemia. Leukemia . 2016;30:555-61.

\section{Affiliations}

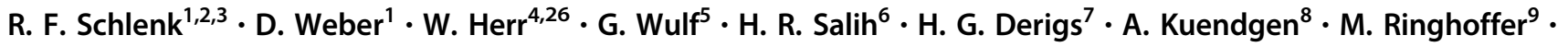
B. Hertenstein ${ }^{10,11} \cdot$ U. M. Martens ${ }^{12} \cdot$ M. Grießhammer ${ }^{12} \cdot$ H. Bernhard ${ }^{13} \cdot$ J. Krauter $^{14} \cdot$ M. Girschikofsky ${ }^{15}$.

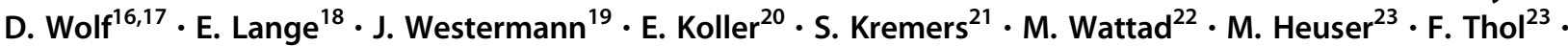
G. Göhring ${ }^{24} \cdot$ D. Haase ${ }^{5} \cdot$ V. Teleanu ${ }^{1} \cdot$ V. Gaidzik ${ }^{1} \cdot$ A. Benner $^{25} \cdot$ K. Döhner ${ }^{1} \cdot$ A. Ganser ${ }^{23} \cdot$ P. Paschka ${ }^{1} \cdot$ H. Döhner ${ }^{1}$

1 Department of Internal Medicine III, University Hospital of Ulm, Ulm, Germany

2 NCT-Trial Center, National Center of Tumor Diseases, Heidelberg University Hospital and German Cancer Research Center, Heidelberg, Germany

3 Department of Internal Medicine V, Heidelberg University Hospital, Heidelberg, Germany

4 Department of Hematology, Medical Oncology and Pneumology, University Medical Center Mainz, Mainz, Germany

5 Department of Hematology and Oncology, University Hospital of Göttingen, Göttingen, Germany

6 Department of Hematology and Oncology, Eberhard-Karls University, Tübingen, Germany

7 Department of Internal Medicine III, Hospital Frankfurt-Hoechst, Frankfurt, Germany

8 Department of Hematology, Oncology and Clinical Immunology, University of Duesseldorf, Medical Faculty, Duesseldorf, Germany

9 Department of Hematology and Oncology, Städtisches Klinikum Karlsruhe, Karlsruhe, Germany

10 Department of Hematology and Oncology, Klinikum Bremen
Mitte, Bremen, Germany

11 Department of Hematology and Oncology, Klinikum am Gesundbrunnen, Heilbronn, Germany

12 Department of Hematology and Oncology, University Hospital of Minden, Minden, Germany

13 Department of Hematology and Oncology, Darmstadt, Municipal Hospital, Darmstadt, Germany

14 Department Hematology and Oncology, Braunschweig Municipal Hospital, Braunschweig, Germany

15 Department of Hematology and Oncology, Hospital Elisabethinen Linz, Linz, Austria

16 Internal Medicine III, University Hospital of Bonn, Bonn, Germany

17 Department of Internal Medicine V, Medical University Innsbruck, Innsbruck, Austria

18 Department of Hematology and Oncology, Evangelisches Krankenhaus Hamm, Hamm, Germany

19 Department of Hematology, Oncology and Tumor Immunology, Charité - Campus Virchow Clinic, Berlin, Germany

20 Department of Internal Medicine III, Hanuschkrankenhaus Wien, 


\section{Wien, Austria}

21 Department of Internal Medicine, Caritas-Krankenhaus Lebach, Lebach, Germany

22 Department of Hematology and Oncology, Hospital EssenWerden, Essen, Germany

23 Department of Hematology, Hemostasis, Oncology, and Stem Cell Transplantation, Hannover Medical School, Hannover, Germany
24 Institute of Human Genetics, Hannover Medical School, Hannover, Germany

25 Division of Biostatistics, German Cancer Research Center Heidelberg, Heidelberg, Germany

26 Present address: Department of Hematology and Internal Oncology, University Hospital of Regensburg,

Regensburg, Germany 